\title{
OPERATIONAL STRATEGIES AND MANAGEMENT OF KFC: AN ENQUIRY
}

\author{
Shah Mujahid Uddin \\ MSc in Project Management, University of Bedfordshire, UK and Deputy Secretary, Government of \\ Bangladesh,
}

Article DOI: https://doi.org/10.36713/epra4262

\begin{abstract}
This is a business case report on one of the world largest fast food chain restaurants Kentucky Fried chicken (KFC) in accordance on its operation management and strategy. As the course requirement, the company has been selected on the preference of my own with a prior approval of the unit leader. The report critically analysis three operation management decision areas as design of goods and services, quality management and supply chain management of KFC with suggestions to better performance. Furthermore, it evaluates the strengths and weaknesses as well as strategies with recommendations for achieving competitive advantages. Finally, the report draws a conclusion with wrapping up the findings.
\end{abstract}

KEYWORDS: Managing Quality, Supply Chain Management, SWOT Analysis, CSR

\section{INTRODUCTION}

The role of operational management has become more diverse and challenging due to present global business context, and rapid product development for customer requirements. Without the effective performance of operations and process management, no company can be sustained and succeed in long term (Slake et al, 2015). Furthermore, Heizer et al, 2017 mentioned that operation management is the costly part of an organization.

Operations management is the set of activities to manage the resources that produces goods and services (Harrison, 1996; Vilder, 2001; Slack, Jones and Johnston, 2013). Operation strategy treat as a mixture of actions and decisions that focuses on visions, goals and capacity of operations which attain the competitive advantages of organization (Slake et al, 2015).

KFC, a subsidiary of YUM! Brands is one of the world largest restaurant chains, maintain the business from Kentucky in United States with 21487 outlets including own managed (3\%) and franchising
(97\%) over the 131countries (Yum, 2018). It is well known for its original fried chicken recipe. (KFC, 2018)

\section{OBJECTIVES}

The report critically analyses the design of goods and services, quality management and supply chain management operation decision areas of KFC. Report also evaluates strengths and weaknesses as well as competitive advantages with recommendations to improve the performance of KFC.

\section{METHODOLOGY}

The study was documentary analysis type. Data were collected from secondary sources like books, research reports, journal, internet etc. The study adopted a critical review method along with the SWOT analysis to depict the fortes and limitations of KFC's operational strategies and management. Data were collected directly from the KFC's official websites. 


\section{SJIF Impact Factor: 6.260| ISI I.F.Value:1.241| Journal DOI: 10.36713/epra2016 ISSN: 2455-7838(Online) EPRA International Journal of Research and Development (IJRD)

\section{DISCUSSION AND ANALYSES: THREE OPERATIONS MANAGEMENT DECISION AREAS OF KFC}

Heizer et al, (2017) identified ten operation management decision areas for business organization. These are design of goods and services, managing quality, process strategy, location strategy, layout strategies, human resources, supply chain management, inventory management, scheduling and maintenance. Among them design of goods and services, supply chain management and managing quality in $\mathrm{KFC}$ are chosen for critical analysis.

\subsection{Design of Goods and services}

Strong product and services play an important role in operation management in the competitive global market. The goal of product design is to develop and implement of the product strategy to achieve the competitive advantages over the counter parts (Heizer et al, 2017). KFC is a Brand that specializes in fried chicken which utilizes the product selection, product definition and product design strategies.

\subsubsection{Product selection}

From the very beginning the founder of the KFC selected the chicken rather than lamb, mutton or beef as a product. Since that KFC provides the goods and services to the customer (KFC, 2018). To maximize success, each of every company focus on limited product such as Honda famous for engines, Intel for microprocessors and Michelin well known for tyres (Waddington, 2018).

\subsubsection{Product Definition}

KFC offers a distinct high-quality product to global market. Shouldice Hospital in USA has expertise on hernia repairs; it is distinct reputation from others (Waddington, 2018). As like as KFC offers a sole product that comes from unique recipe chicken with a blend of 11 herbs and spices (KFC, 2018). The ingredients and taste make the distinct and high-quality product that represents a trade secret.

\subsubsection{Product Design}

Customer needs influence the product design. Due to customer demands, KFC has enriched its menu with other products such as chicken burgers and wraps, salads, desserts, side dishes and soft drinks (KFC, 2018).
A global marketing strategy is varied from local because consumer's preferences differ spontaneously in the world (Peng, 2014). From the product perspective, KFC first identifies the consumer's likes and dislikes and culture before introducing new product. For cultural point of view KFC introduce new strategies that known as 'Go Global, Act Local' (Simmons and Crawford, 2013 cited in Azman et al, 2014). For instance, Malaysia and Indonesia KFC considering the religion perspective, it introduces the Muslim Halal Food. In addition, lack of potato in both countries, KFC start rice item as side dishes (Azman et al, 2014). More over $\mathrm{KFC}$ considered the Islamic issue they introduce Halal food in worldwide. Besides this KFC do some innovations on introducing drive-through window, kiosk and express units. Above all initiatives indicates that KFC business focuses on product and mass customization. However, for the purpose of maintaining brand image, they are keeping consistent with original recipe remained unchanged (CSOFT International, 2013 cited in Azman et al, 2014).

\subsubsection{Generating new products}

KFC has a product improvement team that primarily creates thoughts. Then test the idea is feasible or not. After that, develop the product specification as well as manufacturing and cooking method. Then reviewing the findings and developing the desired food and it also evaluate whether the product meets the customer needs. Finally, the new menu is introduced in competitive markets. It is noticeable that, Yum expensed \$22 million, \$24 million, and \$25 million in 2017, 2016 and 2015 for research and development (Yum, 2018). So, the product development stage covers the concept, feasibility, customer requirements, functional specifications, product specifications, design review, test market, introduction and evaluation with the scopes for teams of product development and the team for design and engineering.

\subsubsection{Suggestions to improve product design performance}

Product decisions are based on one or combination of selection, definition and design of products. Also, it is inevitable that every product experienced the decline phase of its life cycle and company gains most of the profit in maturity stage. (Heizer et al, 2017). Figure-1 shows the maturity level. At maturity points of view organization should take the opportunity as much as possible. KFC should make continuous improvement and innovation in its local side dishes by adding new flavor and taste. Moreover, KFC should add breakfast menu especially for students. This 


\section{SJIF Impact Factor: 6.260| ISI I.F.Value:1.241| Journal DOI: 10.36713/epra2016 ＩSSN: 2455-7838(Online) EPRA International Journal of Research and Development (IJRD)

advantage opens a new window for organization. and avoid uncertainty environments which are Finally, KFC can introduce Six Step decision model mentioned it Heizer et al 2017.

\section{Product Life Cycle}

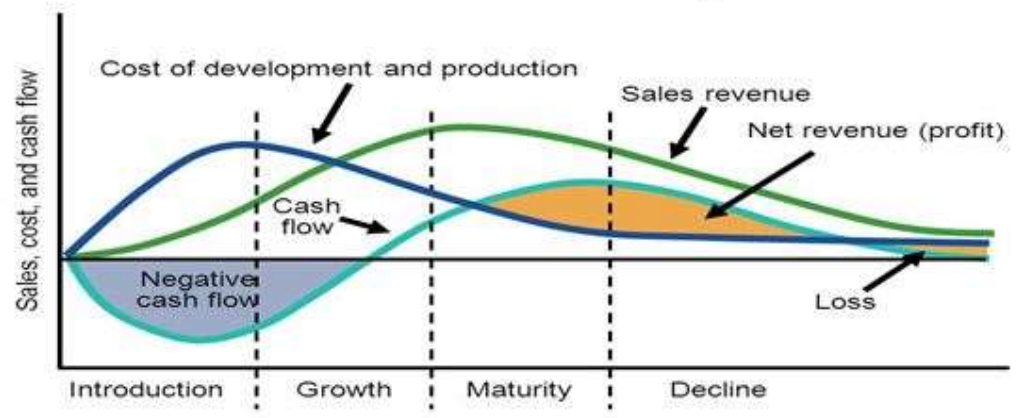

Figure-1: Product life cycle

\subsection{Managing Quality}

Quality management is important for successfully running business activities through keeping customer satisfied. American Society for Quality defines 'The Totality of features and characteristics of a product or service that bears on its ability to satisfy stated or implied needs' (Waddington, 2018).Improve quality increases productivity through sail gains and reduced cost (Heizer et al, 2017).For instance 'The Swiss Army Knife', and 'The Four Seasons Hotel CannaryWharf2' are well known for quality. On other side bed quality as 'fat fingers syndrome' affected the organisation like Swiss Bank in 2009 (Slake et al, 2015). Deming 14 points approach focuses first quality and then global business (Bank, 2000). Considering the Deming 14 points, globally it divided into seven concepts as continuous improvement, six-sigma, employment empowerment, benchmarking, just-intime, taguchi, and knowledge of TQM tools.

\subsubsection{Continuous Improvement}

Fried Chicken is KFC specialize products and it also continuously making in products and services. For instance, they introduce meat free menu especially for vegetarian. This vegetarian menu helps the brand to be more attractive to a larger section of customers. Now 'So Veg, So Good' slogan is treated as part of KFC promotion strategy in India (KFC,2018). In addition, KFC new innovation in product is Nashville Hot Chicken and considering the services is kiosks as well as express out lets. Its drive-through-window operation improves the speed of service (Apte and Renolds, 1995). Yum expended huge amount money on research and development which represent the Shewharts's PDCA (Plan, DO, Check, Act) model.

\subsubsection{Six-Sigma (3.4 defects per million)}

It is applied in KFC by maintaining precision and reducing defects in all products and services. For example, KFC is popular for its original recipe chicken with secret blend of 11 herbs and spices to customers even after more than 70 years for its innovation that proves distinct feature (KFC, 2018).

\subsubsection{Employee empowerment}

Working environment is very important of employees to utilize their skills and capabilities. KFC belongs to a good image in this area. For quality improvement, Yum first develop the employment opportunity like introduce the pension, retire medical and retire savings plan (Yum, 2018). Training and motivational activities boost up the capability that increase the productivity. The restaurants service time cut more than half by improving labor productivity (Apte and Renolds, 1995).

\subsubsection{Quality policy and guideline}

KFC has own quality standards guideline that narrate require direction for food safety and quality as well as quality risk, product production procedure, equipment maintenance, facility standards and accounting control procedures (Yum, 2018; KFC, 2018). An integrated quality approach introduces like, cleanliness, hospitality, accuracy, maintenance, product quality and service along with training, rewarding employee performance. But if the expectations are higher than performance then perceived quality is lower than satisfactory that's leads the customer 


\section{EPRA International Journal of Research and Development (IJRD)}

dissatisfactions (Parasuraman et al, 1985 cited in Nguyen, 2018).

\subsubsection{Suggestions to improve the performance}

KFC should apply TQM tools and techniques for quality management. These includes the fish bone diagram for identifying process element, pareto chart for organizing data, check list for generating ideas, histogram for identifying problems finally statistical process control for defect prevention. KFC may introduce the Body Shop customer focus slogan 'Smile Dammit Smile' that treat customer as potential friend, acknowledge the presence, talk within 3 minutes, offer product advice, always smile with thanks. Moreover, KFC should consider the food safety especially for children. Finally, it is suggested that research, training and development program should be continued for employees.

\subsection{Supply Chain Management}

Supply chain management (SCM) is the combination of activities that purchase, outsource or hire materials or services, later transform them into intermediate goods as sellable final product for consumer (The supply chain council cited in Millar, 2015).

In general, KFC maintains three phases in supply chain. Primarily materials are purchased from multiple suppliers and stored in two different warehouses like normal and cold storage. Then products grounding is done and sold to the customers in desired outlet or locations. In final phase outlets are replenished three times a week through warehouse. Figure-2 shows the phases as an example:

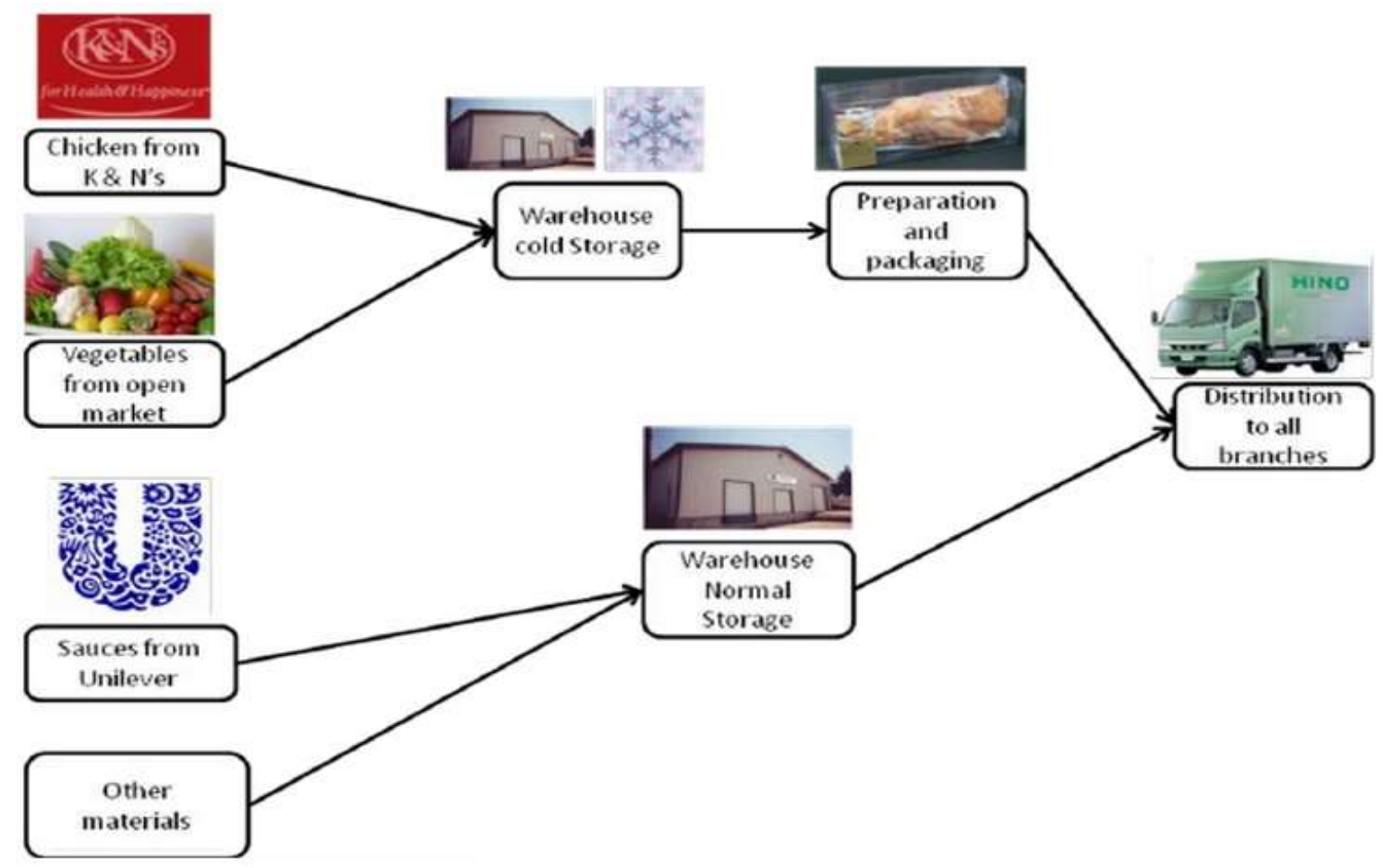

Figure-2: KFC Supply chain phase

KFC and its franchises have approximately 6400 food and paper supplier KFC and franchisers purchased the principle items include chicken, cheese, beef and pork products, paper, packaging materials and outsource or hiring the logistic and warehouse (Yum, 2018).

Buying decision makes the company profitable by lower pricing, reducing quality and inventory cost as well as management cost. As a restaurant business buy 
decision is appropriate. In addition, it is noted that KFC follow the leverage products which is mention in Kraljic portfolio purchasing model (1983).

Considering the six sourcing strategies, KFC chosen the many suppliers' strategy. UK generally sources chicken from local poultry suppliers and rest of the chicken procure from EU, Brazil and Thailand (KFC, 2018). KFC in US and own restaurants main supplier is McLane Food service Inc (Yum, 2018). Pakistan Venky, VH group, $\mathrm{K} \& \mathrm{~N}$ etc are mains suppliers of India division and china procure a major portion from OIS group. In terms logistic chain KFC worked with DHL, QSL and Bidvest logistics.

KFC supply chain risk reduction tactics are effective for multiple suppliers which reduces the dependency, monopoly and risk. Another tactic is careful supplier selection, certification and monitoring. In UK suppliers fulfill the welfare standard, and RSCS select supplier and monitor the activities in UK. Furthermore, KFC reduces the political, economic and legal issues in supply chain by franchising. But the recent experience of UK is not satisfactory. Due to change in supply chain, it faces chicken shortage that causes 900 out lets were faced troubled in February 2018(The Guardian, 2018). This happened for communication and relationship gap. Wilding (2018) mention that it is important to managing relationship with existing or former and implication for upcoming partners as well as collaborations.

\subsubsection{Suggestion to improve performance}

KFC should build the supply base stages like supplier evaluation through supplier certification, supplier development, Negotiations and contracting. Supplier should be more integrated in operations approach through training. Moreover, multiple transportation and warehouse are prerequisite to overcome the supply risk. Furthermore, before changing in supply change, they should allocate proper budget on contingency. Finally, KFC should give more attention on sustainable eco friendly supplier and build up collaboration as well as relationship.

\section{SWOT ANALYSIS AND ACHIEVING COMPETITIVE ADVANTAGES IN KFC: A CRITICAL OVERVIEW}

SWOT analysis reflects, how well a company's strategy is working, a proper understanding of the resource capabilities and deficiencies, it's market opportunity, and the external threats to its future is essential. Figure-3 shows the competitive advantage which focuses on differentiation, cost and response (Heizer, Render and Monson, 2016). According to slack et al. (2015), the five competitive priorities are cost, quality, speed, flexibility and dependability that's relating to operations strategy. In addition, 'PESTEL' analyses helps to identify the external factors for setting strategies. Table-1 shows the Strengths and Weaknesses of KFC.

Table-1: SWOT analysis of KFC

\begin{tabular}{|c|c|}
\hline Strengths & Weaknesses \\
\hline $\begin{array}{l}\text { 1. One of the largest restaurant chains. } \\
\text { 2.Brand Image } \\
\text { 3. Product Uniqueness/ Differentiation. } \\
\text { 4.High quality foods } \\
\text { 5. Quick service } \\
\text { 6.Strong research and development activities } \\
\text { 7. Environment friendly } \\
\text { 8.Corporate Social Responsibility (CSR) }\end{array}$ & $\begin{array}{l}\text { 1. High price } \\
\text { 2. Some unethical supplier } \\
\text { 3. Logistic supply chain }\end{array}$ \\
\hline Opportunities & Threats \\
\hline $\begin{array}{l}\text { 1.Franchises } \\
\text { 2.Cross Culture } \\
\text { 3.Innovations in new idea } \\
\text { 4.Collaboration and partnership }\end{array}$ & $\begin{array}{l}\text { 1.Market competitors } \\
\text { 2.Substitute product } \\
\text { 2.Avian flue } \\
\text { 3.High calorie food }\end{array}$ \\
\hline
\end{tabular}


SJIF Impact Factor: 6.260| ISI I.F.Value:1.241| Journal DOI: 10.36713/epra2016 ISSN: 2455-7838(Online)

EPRA International Journal of Research and Development (IJRD)

Volume: 5 | Issue: 4 | April 2020

- Peer Reviewed Journal

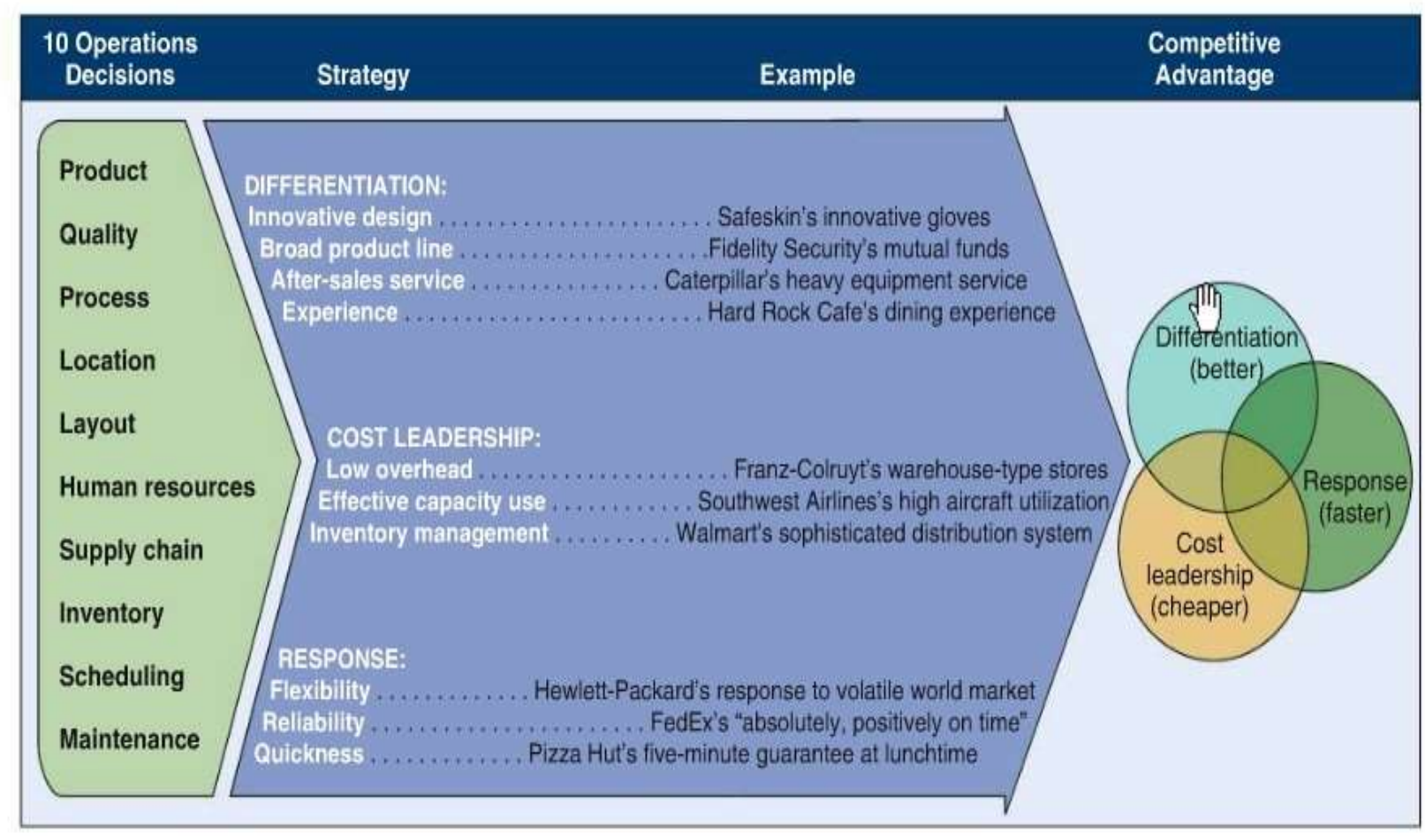

Figure 3: Operation Decision, Strategy and Competitive Advantage

\subsection{Product Uniqueness/Differentiation}

Differentiation is interlinked with ensuring and providing uniqueness in goods and services. In order to grave market and consumers satisfaction, organizations try to make product different in nature. From the starting of KFC, their product is popular to the fast food lovers due to its original chicken recipe which still remain unchanged (Yum, 2018). This secret recipe, outstanding quality and taste made differentiation and increase brand image that leads the competitive advantages. For instance, Crittenden et al (2015) mention that food and beverage secrets dominate the business -to-customer marketplace. Moreover, brand image can use intellectual property as strategic weapons (Reitzig, 2004).

\subsection{Cost leadership}

An organisation attains advantages by delivering low cost products to the customers. In this strategy, $\mathrm{KFC}$ is not performing well. Final products price is dependent raw materials prices. KFC price strategy is if the ingredients price increase, the extra amount pass to the customers (Yum, 2018). But any price increase might lead to consumer switching the other fast food or stop buying (Azman et al, 2014)

\subsection{Responsive}

Responsive is referred to flexibility, reliability and quickness in product development and delivery. In this regard, before introducing a new product they conducted survey the customer requirements (Yum, 2018; Simmons\& Crawford, 2013 cited in Azman et al, 2014). On other side, KFC now introduce collectrametric, a pressure fryer to prepare fried chicken quickly. It also maintains the dependability through quick delivery promise.

\subsection{Market competitor}

Peter's five forces model focuses on immediate rivals, potential entrants, customers, suppliers and substituted products.KFC immediate rivals are McDonald, Subway, Burger King, Dominos, Pizza Hut and Taco Bell. In UK 50\% of the fast food restaurants has managed by McDonald (28.8\%), KFC (12.5\%) and Subway (8.7\%) (Nguyen et al, 2018). Each of every company tries to increase the participation ratio by introducing cheapest quality product. At the same time customer taste is changing and preferable one takes the competitive advantages (Shuailing and Zhi, 2015). Adequate information on rivals can reduce the competitive disadvantages. 


\section{EPRA International Journal of Research and Development (IJRD) \\ Volume: 5 | Issue: 4 | April 2020 \\ - Peer Reviewed Journal}

\subsection{Product quality and fast service delivery}

Now a day's product quality and fast service delivery is prerequisite for business strategies.KFC is famous for quality and service in chain restaurant. If any customer becomes ill due to food safety issues, authority temporarily close the out late (Yum, 2018). By the quality improvement program 'drive-throughwindow, KFC profit margin increase from 5-9 percent, labor productivity increases $12.3 \%$ in test program (Apte and Reynolds, 1995 cited in Russell and Taylor,1998). KFC restaurant try to win customers expectations by giving better services for creating a loyal customer base (Rahman et al, 2017). But in china, Chicken supplier are criticized for using excessive antibiotics and growth hormones in poultry which is unethical (Bloomberg view, 2014). Moreover, KFC suppliers have been criticized for using soybean which was cultivated in Amazon rain forest.

\subsection{Corporate Social Responsibility (CSR)}

KFC has corporate social responsibility as student scholarship, sponsorship, and hunger relief effort to the interest of mass people (KFC, 2018). For instance, in 2014, after earthquake Lu Dian, China, KFC donate two million yuan to disaster area and China KFC Dawn fund helped the 15000 poor students (Shuailing and Zhi, 2015). According to Archie Carroll's model (Figure-4), CSR increase the Company's sustainability of business and corporate citizenship. It helps to develop the relationship among the suppliers, business partner, employees and community that leads to enhance the long-term advantages.

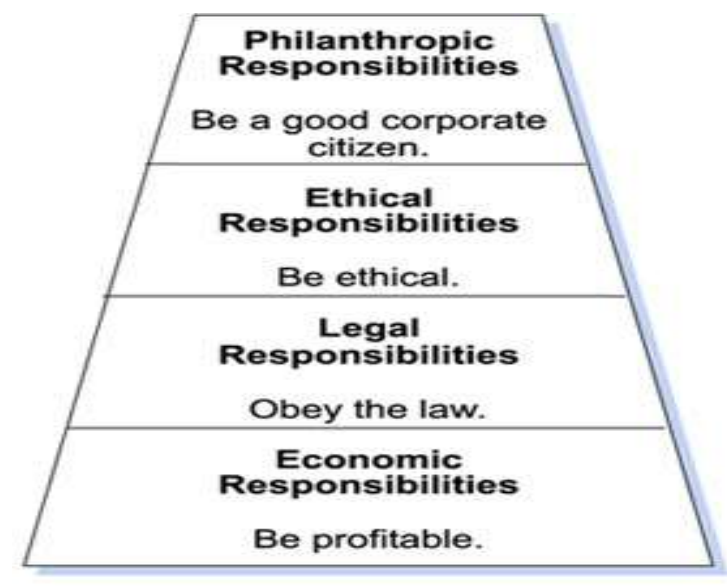

Source: Carroll (1996)

Figure-4: Archie Carroll's model

\section{CONCLUSION AND RECOMMENDATIONS}

In conclusion, this report finds that the global business is becoming more complex and competitive in terms operations decision areas and strategy. It also finds, operations management and strategy make the competitive advantage. Every decisions areas and strategy are distinct from other. Thus, right choice of decisions areas and their appropriate strategy are highly important for advantages.

From this report it is identified that KFC biggest strength is its brand image based on colonel's legacy and its product design and quality of original chicken recipe which makes the market leadership. But considering the challenges, it is recommended that KFC should give more attention on supply chain and cost effectiveness.

After analyzing all the issues, the study finally recommends the following points:

a. Considering the food safety and quality KFC should not have any relationship with any unethical organization to avoid all negative criticism. KFC should introduce small improvement through total quality management. Besides this packaging materials should be used environment friendly.

b. KFC will be able to take more advantages by its original recipe product as an intellectual property. 


\section{SJIF Impact Factor: 6.260| ISI I.F.Value:1.241| Journal DOI: 10.36713/epra2016 ＩSSN: 2455-7838(Online) EPRA International Journal of Research and Development (IJRD) \\ Volume: 5 | Issue: 4 | April 2020 \\ - Peer Reviewed Journal}

c. KFC need to more emphasis on CSR. It will be able to increase band image which will hit the sails gain and competitive advantage.

\section{REFERENCES}

1. Apte, U., M., and Reynolds, C. (1995). Quality management at Kentucky fried chicken, Interfaces, 25 (3), 6-21.

2. Azman, I., Elbakoush, A., Y., Hashom, H., and Subhan, M. (2014). Indonesia and Malaysia consumers: Are they different in preference? A comparative study of KFC Malaysia and KFC Indonesia's marketing strategy. Papers Presented at the $5^{\text {th }}$ International Studies, December, Kuala Lumpur, Malaysia

3. Bank, J. (2000). The Essence of Total Quality Management, $2^{\text {nd }}$ ed, Edinburgh Gate: Pearson Education.

4. Crittenden, W., F., Crittenden, V., L., and Pierpont, A. (2015). Trade secrets: Managerial guidance for competitive advantage, Business Horizons, 58, 607613

5. Harrison, M., (1996) Principles of Operations Management, London: Pitman Publishing

6. Heizer, J., Render, B. and Munson, C. (2017). Operations Management: Sustainability and Supply Chain Management, $12^{\text {th }}$ global ed, Harlow: Pearson

7. KFC (2018). Company Informations [Online] https://www.kfc.com. [2018, 24 April]

8. Millar, M. (2015). Global Supply Chain Ecosystem, London: Kogan Page Limited

9. Nguyen, Q., Nisar, T., Knox, D., and Prabhakar, G. (2018). Understanding customer satisfaction in the UK quick service restaurant industry: The influence of the tangible attributes of perceived service quality, British Food Journal, 103 (1), 36-45.

10. Reitzig, M. (2004). Strategic management of intellectual property, MIT Sloan Management Review, 45 (3), 35-40

11. Rahman, M., Hosain, I., Mitu, F., Mustafi, M., A., A., and Miah, M. (2017). An examination of the effects of customer expectation, perceived quality, and customer satisfaction on customer loyalty: A case study on KFC restaurant, International Journal of Engineering and Applied Science, 12 (2), 58-64

12. Russell, R., S., and Taylor III, B., W. (1998). Operations Management: Focusing on Quality and Competiveness, USA: Prentice Hall, Inc.

13. Shuailing, L., and Zhi, Y. (2015). KFC development in Chinese market- Based on the social responsibility and ethics, Canadian Research \& Development Center of Science and Cultures, 10 (3), 142-146

14. Slake, N., Brandon-Jones, A., Johnston, R., and Betts, A. (2015) Operations and Process
Management: Principles and Practice for Strategic Impact, $4^{\text {th }}$ ed, Edinburgh Gate: Pearson Education.

15. Slack, N., Jones, A., B., and Johnston, R. (2013). Operations Management, $7^{\text {th }}$ ed, Harlow: Pearson

16. The Guardian (2018) KFC struggle to give chicken away as store supply crisis continuous, The Daily Guardian [online], https://www.theguardian.com/business/2018/feb/22/ kfc-surplus-chicken-charities-store-supply-crisis [2018, 24 April]

17. Vilder, C., (2001). Operations Management, Oxford: Heinemann Educational Publishers.

18. Waddington, J. (2018). Guiding learning, [Lecture to MSc Project Management], BSS052-6: Project and Operation management, University of Bedfordshire, $16 \quad$ April, 2018, https://bero.beds.ac.uk [2018, 19 April.]

19. Wilding, R. (2018). Why did the chicken not cross the road? [Online], www.kilturk.org.uk [2018, 24 April]

20. Yum! Brands (2018). Annual Report [Online] https://www.yum.com/annual report [2018, 24 Aprill] 